\title{
A guideline to link the off-design performance of a micro-gas turbine to a heavy-duty gas turbine in a test rig that aim to investigate flexibility of GTCC
}

\author{
Tommaso Reboli ${ }^{1 *}$, Iacopo Rossi ${ }^{1}$, Alberto Traverso $^{1}$ and Giorgio Torelli ${ }^{2}$ \\ ${ }^{1}$ Università degli Studi di Genova, DIME, 16145, Genoa, Italy \\ ${ }^{2}$ Tirreno Power SpA, 17047, Valleggia di Quiliano (SV) - Italy
}

\begin{abstract}
In the era of coal power station phase-out, natural gas fired combined cycle will drive the energy transition towards sustainable power generation. In a panorama of strong requirement for grid flexibility and non-dispatchable renewable penetration, the survival of a thermal power plant is strictly linked with operating successfully in compensating the renewable fluctuating production through flexible generation. The Italian case is taken as reference, considering that energy transition and renewable energy penetration may have similar effects also in different countries. In this direction, a test rig to investigate gas turbine compressor inlet conditioning techniques has been developed at the Tirreno Power laboratory of the University of Genoa, Italy. This is based on a Turbec T100 micro gas turbine (or microturbine), a Mayekawa heat pump and a phase-change material energy storage. The whole test-rig is virtually scaled up, through a cyber-physical system, to emulate a real $400 \mathrm{MW}$ combined cycle, with the heat pump governing the inlet conditions at the compressor. The microturbine is therefore used as the physical feedback for the system, whilst the steam bottoming cycle is simulated in real-time according to microturbine operation. The scope is to present the test rig and the procedure adopted to virtually scaleup a microturbine to a heavy-duty GT. the advantage of using microturbine for testing combined cycle flexibility options lays also on the possibility to make accelerated tests and to simulate multiple situations in compressed time windows.
\end{abstract}

Keywords: combined cycle, flexibility, renewables, microturbine, thermal energy storage

\section{Introduction}

Due to their capability in operating fast transients, Gas Turbine Combined Cycle (GTCC) power plants are the main drivers for the energy transition process. Impact of renewables is significantly affecting the way the energy is provided and delivered at global level. Particularly, the expected scenario to 2050 is considering a higher impact of solar energy compared to wind and biomass utilization due to sustainable criteria and social acceptance. The solar is expected to provide $39-44 \%$ of primary energy share, with $75 \%$ share of the electrical generation [1]. It is therefore of interest to pose attention on those developed countries, which have high solar share and high renewable energy share. This is the case of Spain, Germany and Italy [2][3]. With the increasing of intermittent RESs in the energy share, the intraday market rises in importance and policy makers have to accept an increase in energy price during off-peaks period - also to sustain dispatchable plants with low marginal cost [4]. The Italian case is representative of these trends: solar has a predominance in the RES share and is distributed at micro scale (the presence of CSP is not even close to be as consistent as in Spain). This has the effect on the market price, where the Standard National Price (PUN) oscillates between 45 and 80 $€ / \mathrm{MWh}$ on yearly basis, as shown by Fig. 1 [5].

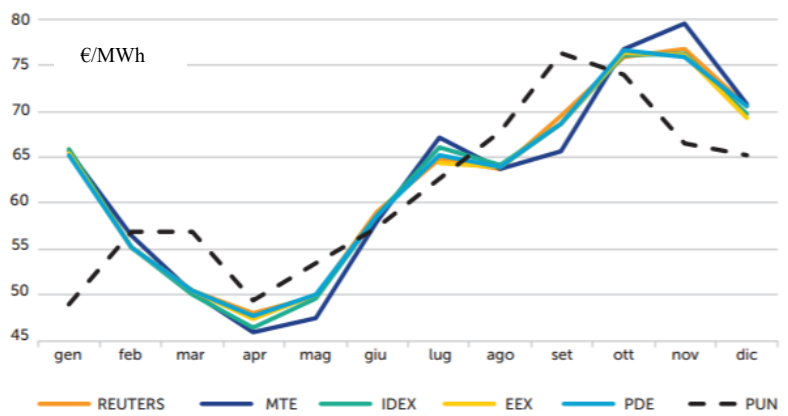

Fig. 1. Price oscillating during infraday Italian market 2018

\footnotetext{
* Corresponding author: tommaso.reboli@edu.unige.it
} 


\subsection{Background and motivation}

The aforementioned Italian case is just representative of the energy market situation that the EU countries are facing or are going to, due to the continental energy transition process. The wide penetration of distributed renewable systems, with particular relevance of solar and wind systems, creates an effect on the market that will be experienced, with some deviations, also on those countries that are moving to a more distributed, renewable based energy framework. The coal phase-out decided by government and the European general trend about decarbonization puts more pressure on the GTCCs, which are expected to drive the energy transition. OEMs understood that the opportunity for GT to drive the changes - and not to be driven - lays in focusing on operational flexibility, fuel flexibility and work under a Power-to-X-to-Power chain. This is the reason why Ammonia and Hydrogen stroke back consistently in recent years. Combustion of pure Ammonia has been widely analysed by Kobaiashi et al. [6]. Hydrogen rises in interest particularly for the technology presented by Ansaldo Energia at Turbo Expo 2019 [7].

At the same time, several ongoing studies are addressing flexibility issues of the existing and running power plants. Solutions investigating the compressor to reduce Minimum Environmental Load (MEL), with modifications to IGVs, Blow-Off line and temperature conditioning for retrofitting, have been analysed in [8] and [9]. In [10] a series of cascaded latent heat storages has been proposed to improve off-design performance of existing combined cycle. Yongy Li et al. studied a backpressure modulation at the end of the HRSG to improve part load performance, assessing an improvement in efficiency up to $1.76 \%$ [11]. What emerges from this short literature analysis is that the interest to improve part-load performance with attention to MEL is evident and still on-going.

\subsection{Scope of the work}

Following the conceptual study performed in [12] by the research team of the Authors, this work poses the bases for the first experimental assessment of flexibility enhancement by coupling Heat Pumps (HP) to GTCC, together with thermal energy storage (TES). The overall aim is to demonstrate the potential of a HP+TES system when operated in cooperation with a GTCC to act as an electrically equivalent energy storage, therefore enhancing the flexible operation of the GTCC.

This paper describes the design and development work of a test rig to study flexibility techniques for combined cycles. The investigated system is a cyber-physical representation of a full size GTCC. This approach integrates real hardware, composed by a heat pump, a storage and a microturbine (mGT), and real time software. The latter uses the outputs of the mGT to scale them up and feed a bottoming steam cycle, simulated by a real-time model. The presentation of the rig and the approach to link the mGT performance to those of an equivalent heavy-duty GT represent the core of this work.

\section{Concept and test rig description}

\subsection{Installed Hardware description}

The Thermochemical Power Group (TPG), a research group of the University of Genoa, installed a facility for studying flexibility of combined cycles through compressor inlet conditioning via heat pump and coupled with a dedicated thermal energy storage. The rig is located at the University labs hosted within the Tirreno Power CCGT. A theoretical analysis of system performance is presented in [12] by Sorce et al. who focuses on the operational issues of a GTCC with HPTES systems and introduces two different layouts: "power oriented" and "cogenerative". The power oriented one, which is devoted to produce electrical energy only, is considered in the present paper. Figure 2 shows the idea behind the test rig. The test rig facility represents the actual hardware, which is involved in the lab, with the most important components in terms of valve, pumps and heat exchangers. On the top of the figure, a representation of the real time hardware which emulates the GTCC is given, together with the connection points with the facility. The connecting point is the mGT, which is used as connection media between the target plant and the actual one. The current working conditions are scaled up and given to the model which emulates a 1+1 GTC, to which the HMI/Control system is interfaced. In Fig. 2, the P\&ID shows:

- Turbec T100 microturbine (mGT),

- Inlet conditioning heat exchanger (INT - Fig. 4),

- $10 \mathrm{kWel}$ Heat Pump (HP) by Mayekawa (working fluid: butane), shown in Fig. 3,

- Thermal Energy Storage (TES).

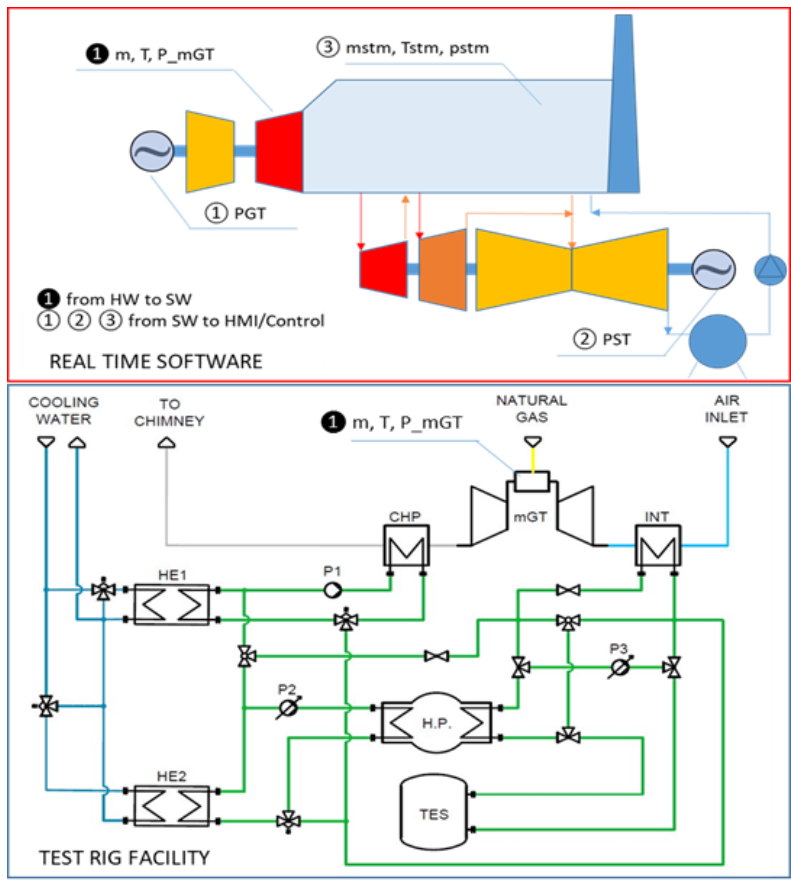

Fig. 2. Pilot plant P\&I and interaction with real-time model

The rig is composed by other components fundamental for the proper operation and thermal management, like HE1,HE2 and CHP heat exchangers and P1 P2 and P3 circulating pumps. 
In particular, by acting on the multiple three-way valves and the circulation pumps it is possible to activate several sub-circuits in order to let the system to operate in different configurations [14]:

- GTCC only, when GTCC is operating in traditional way, without any change in compressor intake temperature,

- CHP heat sent to INT: GTCC with compressor intake heated with heat released by $\mathrm{mGT}$,

- HP to TES: in this case, no temperature change is imposed to the compressor intake, however the Heat Pump can be seen as an auxiliary non dissipative load

- HP to INT heating: the heat pump is on and heating up the compressor intake and delivers cold energy to the TES. This operational mode is beneficial to improve MEL performance, by reducing power (due to absorption of HP and increase of compressor inlet temperature) and increasing efficiency (as demonstrated by in [12]),

- HP to INT cooling: the HP is used to cool down the compressor intake temperature to enhance the microturbine/GTCC net electric power, despite the parasitic consumption of HP. ,

- TES to INT: by acting on the P3 variable circulating pump the cold energy stored in the TES can be delivered to INT heat exchanger in order to cool down the compressor intake temperature, maximizing the boost in microturbine/GTCC net electrical power.

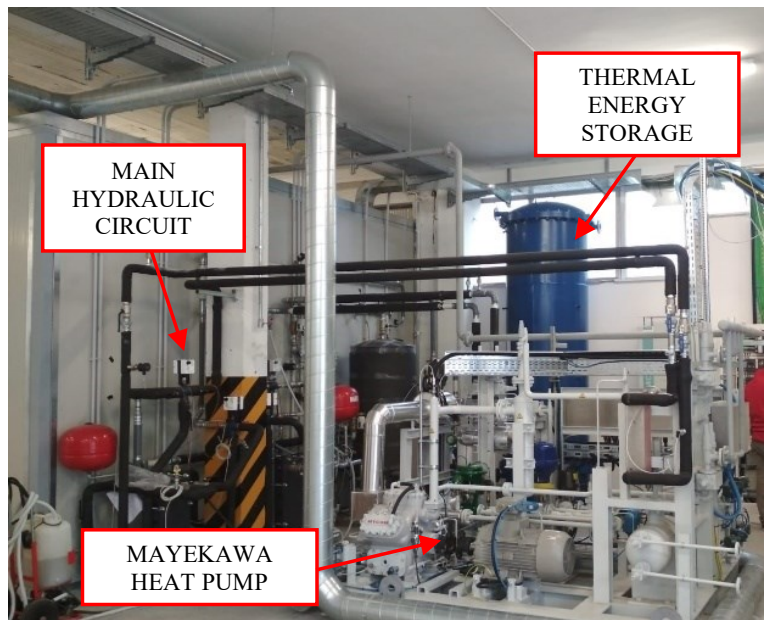

Fig. 3. General view of the test rig, with the main components highlighted

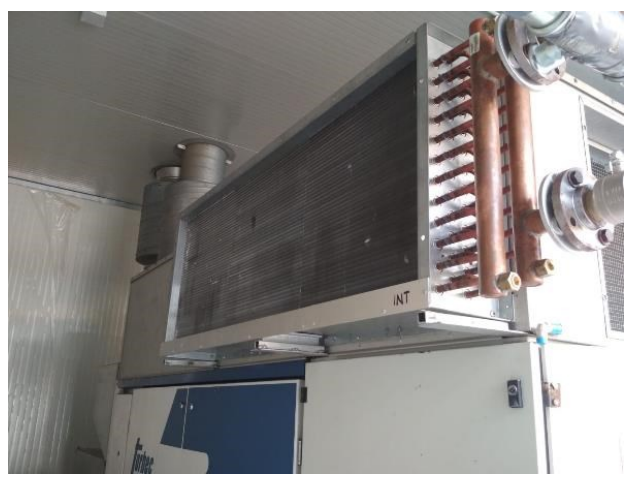

Fig. 4. INT HX installed at mGT intake

In order to operate with low temperatures, the plant is filled with a water-glycol mixture, that is the thermal vector fluid. As already mentioned, one of the key component of the plant is the cold thermal energy storage (TES - shown in Fig. 5), that is essentially a shell $\&$ tube heat exchanger where the water-glycol vector fluid flows inside the pipes, which, on the shell side, are in contact with a Phase Change Material (PCM) having the Phase change temperature at $5^{\circ} \mathrm{C}$. able to store around $100 \mathrm{kWh}$ of thermal energy and to share a peak power of $40 \mathrm{~kW}$.

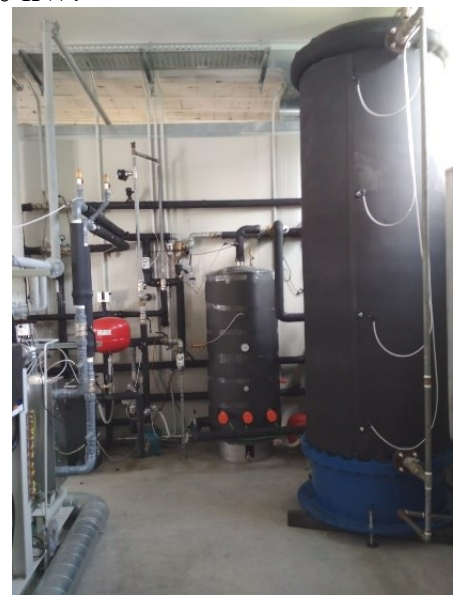

Fig. 5. Detail of Thermal Energy Storage (on left) and plant hydraulic circuit

As emerged from [13], the usage of the storage is the most efficient way to perform inlet cooling in this configuration, but it is limited by the storage capacity itself. Therefore, the storage is used until it can provide energy during the on-peak period - i.e. when the plant is running at full load. Once the storage is eventually discharged, intake cooling can be ensured by the HP, which, however, affects slightly the power boost and the GTCC due to its parasitic consumption. The control system of such complex system has been already presented in its conceptual form in previous work of the group.

\subsection{Real time model}

The real time model of the bottoming steam cycle is a fundamental component of the test rig, as it is designed to emulate the bottoming cycle and feeds back directly the control system for power control. The reference [14] is suggested to have detailed information on the modelling side, which will be integrated with the real hardware in this case. In this arrangement, the microturbine is then used to give a physical feedback on the power plant side and its outputs must be scaled-up to properly emulate a heavy duty gas turbine (GT).The bottoming cycle dynamic model has been developed in collaboration with CRIEPI, Japan: the model details and validation data can be found in [15].

The bottoming cycle dynamic model is able to compute main parameters such as drum pressure, temperatures around the HRSG, ST power, condenser conditions etc. [14] according to ambient conditions and to the current working point of the GT in terms of power, mass flow and exhaust temperature at the HRSG inlet. Fig. 2 explains how the facility interacts with the model and how this is used in the loop with the control system. 


\section{Test rig arrangement}

\subsection{Turbec T100 analysis}

The Turbec T100 is a $100 \mathrm{kWe}$ micro gas turbine fed by methane capable to produce $150 \mathrm{~kW}$ th of thermal energy and spinning at $70000 \mathrm{rpm}$., the involved engine has several hours of operation logged, therefore an analysis on the actual conditions of the engine was carried out underlying a substantial derating of the system - as well as an overview of the off-design performance of the system at the present status. This is particularly important to correlate the performance under inlet conditioning influence with the ones expected on the real GTCC power plant. A discussion on the influence of the ambient temperature at maximum load must be carried out consequently. In literature, Caresana et al. presented a validated model on the T100 obtaining some correction curves [16]. Similar approach has been done by Ferrari, working under controlled ambient conditions [17]. The obtained correction curves were slightly different from what have been proposed by Caresana and his collaborators. Still, what they proposed was not applicable in this case, as the considered T100 has been found to operate under strong derating condition together with undergoing a severe influence by ambient temperature. Fig. 6 report a consistent loss in maximum power and efficiency: at ISO conditions, i.e. $15^{\circ} \mathrm{C} \mathrm{T}_{\mathrm{amb}}$, the actual machine is providing abut $87 \mathrm{kWe}$ (instead of $100 \mathrm{kWe})$ at an efficiency reduced of almost 4 percentage points from the original level. The reasons behind this strong derating have been investigated in a previous work published by the authors and they are mainly related to its strong number of startup and shutdown and the exposure to environmental factor (the engine was originally installed outdoor to provide energy for the Savona Campus)

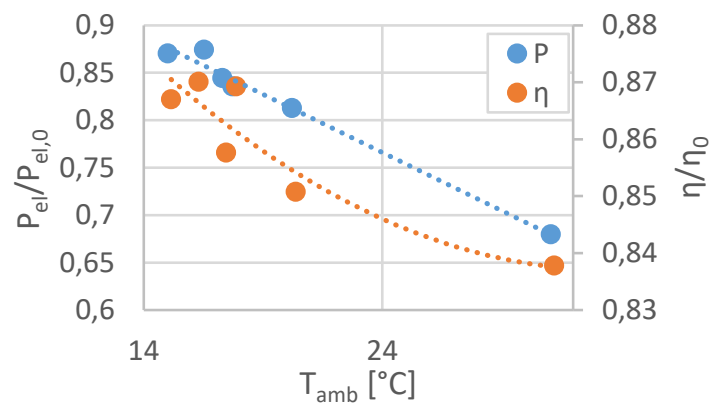

Fig. 6. Power and efficiency derating due to compressor intake temperature increase

Points reported in the two aforementioned graphs are obtained at steady-state conditions and derived from an average over 5 minutes of operation at the selected point. Considering off-design analysis (Fig. 7), three different ambient temperatures have been considered, that are $15^{\circ} \mathrm{C}, 20^{\circ} \mathrm{C}$ and $30^{\circ} \mathrm{C}$. It is possible to notice how the efficiency varies with temperature, in particular the relative improvement at low loads with respect to full load conditions. This behaviour at part load is victim of the control strategies implemented: the counter check will be carried out by operating the system at constant speed rather than at constant TOT as in this case. The influence of TOT at minimum load is essential to understand the off-design performance of the system, particularly because the power at minimum load is not essentially linked to any minimum condition of load for the microturbine. In fact, the T100 model is able to operate at $20 \mathrm{~kW}$ for any ambient temperature. The MEL of a heavy duty GT is, instead, strictly dependent on ambient conditions and varies consequently.

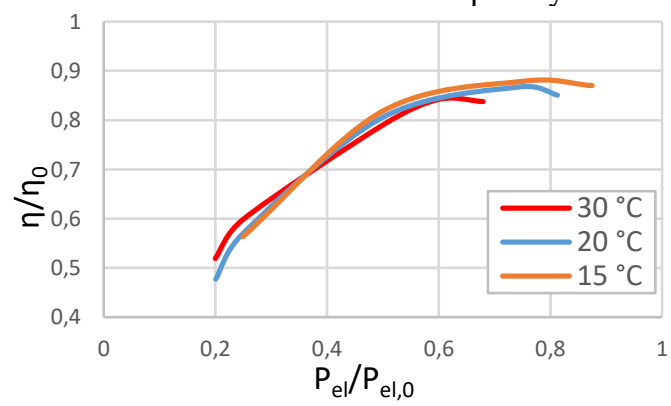

Fig. 7. Off-design performance at different ambient temperatures

Therefore a different strategy for identifying an equivalent MEL on the mGT is adopted, which is related to the different approach in the control system. The minimum load of a heavy duty gas turbine is related to a series of constraints linked to operation of the system, emissions at part load, compressor load and so on. Plus, the bottoming cycle requires always the TOT within some operating range. In the microturbine this kind of issues are not present or less influent (the latent heat is used to recover energy in a regenerated cycle, but it is not feeding any bottoming cycle). The control system of the $\mathrm{mGT}$ reduces the rotational speed at constant TOT for reducing the power output (equivalent to varying the IGV in a constant speed GT). Still, after a certain point, to pursue more flexibility, the control system operating in grid connected mode (i.e. at constant TOT) is able to reduce the setpoint of the TOT itself to reach the $20 \mathrm{~kW}$ threshold in every condition. This change in the setpoint has been found to be dependent on ambient temperature (Fig. 8). Therefore, in this work, such change on TOT setpoint is used as the equivalent MEL for the larger GT. In the end, it is possible to recap that:

- The minimum load of the mGT is considered the load from which the setpoint in the TOT is changed (for every temperature)

- The TOT of the mGT results therefore to be constant in the operation field of the cyber-physical system i.e. when it is used to emulate the GTCC

- The variation with the load of the TOT of the heavy-duty GT working in combined cycle configuration is straightly implemented as there is no need to create a matching with the mGT condition (which is, as explained, always constant in the considered working field)

The data referring to the heavy duty gas turbine have been obtained from GateCycle, considering a Class-F GT arranged in a combined cycle working in $1+1$ configuration. The off-design performances of the machine have been confirmed by the OEM [18].

The turbine is a $270 \mathrm{MW}$ operating at $40 \%$ efficiency for a total net power generation of $400 \mathrm{MW}$ at ISO conditions in combination with the bottoming cycle. 
Such reference CCGT has been investigated at simulation level considering the performance of the plant at $15^{\circ} \mathrm{C}$ and $30^{\circ} \mathrm{C}$ of ambient temperature.

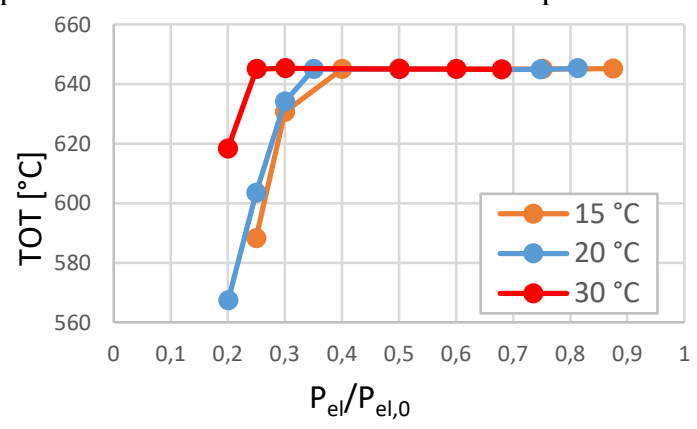

Fig. 8. TOT setpoint variation with Tamb and load

The deviations in linearity that Fig. 9 shows in different parameters are forced to disappear by Tab. 2 and Tab. 3 by putting in relations point per point each part load conditions. This gives the possibility to match and couple the full off-design maps of the duo.
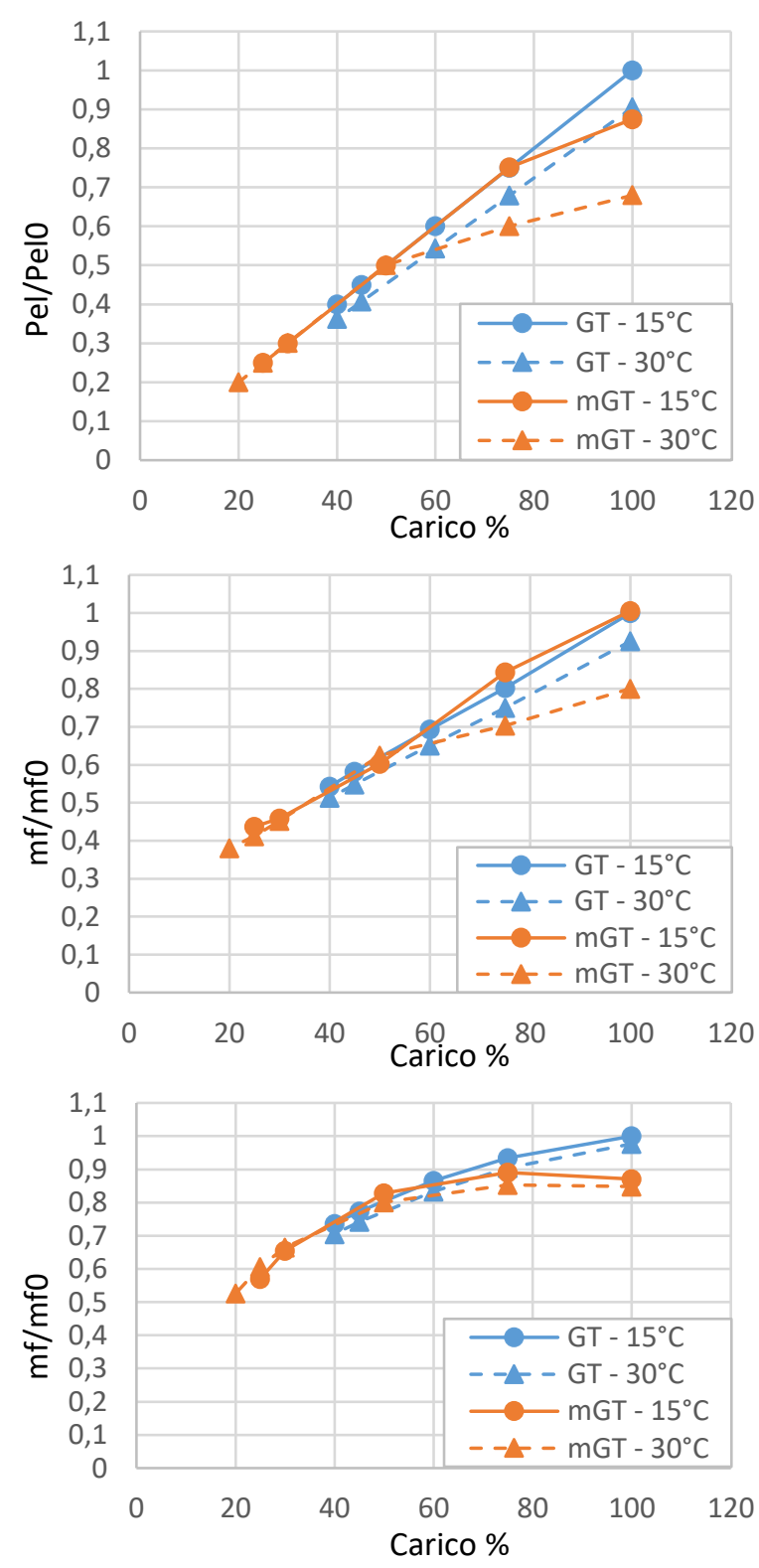

Fig. 9. Comparison of non-dimensional operating parameters for the microturbine and the heavy-duty GT at different ambient temperature

\subsection{Scale-up}

Mathematical non-dimensional correlations have been developed in order to link the two plants: the overall objectives is to provide a cyberphysical representation of the whole GTCC, thanks to the upscaling of the mGT and to the real time software running in parallel. The first step, is, of course, linking the microturbine operating point to the GT only operating point. The minimum load for the microturbine has been considered to be the load corresponding to the reduction in TOT setpoint, according with what has been described previously and showed in Fig. 8. Tab. 1 summarizes the full load and the minimum load of the two systems under different ambient conditions. Turbine outlet temperature of the T100 is considered constant, as a consequence of the analysis carried out in the previous section.

\begin{tabular}{|l|l|r|r|r|}
\cline { 2 - 5 } \multicolumn{2}{c|}{} & \multicolumn{1}{c|}{$15^{\circ} \mathrm{C}$} & \multicolumn{1}{c|}{$20^{\circ} \mathrm{C}$} & \multicolumn{1}{c|}{$30^{\circ} \mathrm{C}$} \\
\hline Pel T100 [kW] & FL & 87.5 & 81.3 & 68.0 \\
\cline { 2 - 5 } & ML & 40.0 & 35.0 & 25.0 \\
\hline Pel GT $[\mathrm{MW}]$ & FL & 270 & 260 & 240 \\
\cline { 2 - 5 } & ML & 110 & 105 & 100 \\
\hline
\end{tabular}

Tab. 1. Comparison between the T100 and the Heavy-Duty GT in terms of full and minimum load at different Tamb

Therefore, the focus is placed on turbine power, fuel flow and air mass flow. Starting from the influence of the ambient temperature on the power output it possible to resume that:

- The Turbec undergoes a decrease in load of $1.2 \mathrm{~kW}$ per ${ }^{\circ} \mathrm{C}$ degree

- The heavy-duty GT loses $1.7 \mathrm{MW}$ per ${ }^{\circ} \mathrm{C}$ degree In consideration of the impact of the ambient temperature on the two systems, it is possible to relate the two generation units thanks to Equation 1 (full load conditions) and Equation 2 (minimum load conditions).

Full Load

$$
\left(\frac{P_{e l}}{P_{e l, 0}}\right)_{G T}=0.5246+0.541 \cdot\left(\frac{P_{e l}}{P_{e l, 0}}\right)_{m G T}
$$

Minimum Load

$$
\left(\frac{P_{e l}}{P_{e l, 0}}\right)_{G T}=0.3+0.25 \cdot\left(\frac{P_{e l}}{P_{e l, 0}}\right)_{m G T}
$$

The same approach has been adopted for the fuel flow consumption of the two systems. Equation 3 is referred to full load and Equation 4 is referred to minimum load conditions.

Full Load

$$
\left(\frac{m_{f}}{m_{f, 0}}\right)_{G T}=0.3597 \cdot\left(\frac{m_{f}}{m_{f, 0}}\right)_{m G T}+0.6355
$$

Minimum Load

$$
\left(\frac{m_{f}}{m_{f, 0}}\right)_{G T}=0.2197 \cdot\left(\frac{m_{f}}{m_{f, 0}}\right)_{m G T}+0.4219
$$




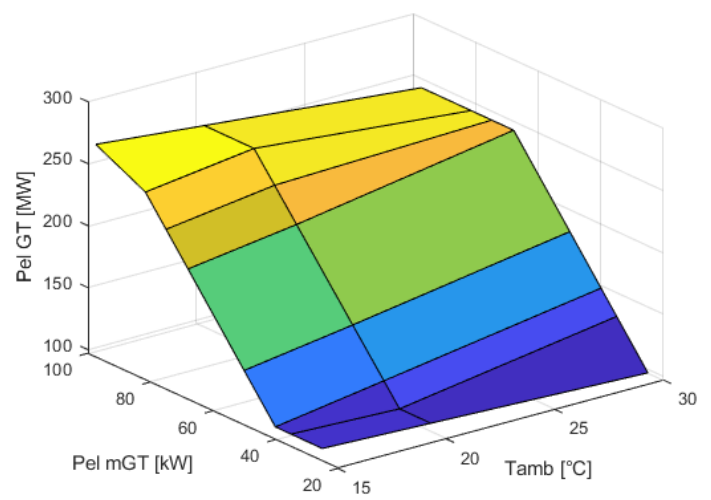

Fig. 10. Operating map linking mGT and heavy-duty GT electric powers at different ambient temperature

\begin{tabular}{|c|l|r|r|r|}
\cline { 3 - 5 } \multicolumn{2}{c|}{} & \multicolumn{3}{|c|}{$\mathrm{P}_{\mathrm{el}} \mathrm{GT}[\%]$} \\
\cline { 3 - 5 } \multicolumn{1}{c|}{} & $15^{\circ} \mathrm{C}$ & \multicolumn{1}{c|}{$20^{\circ} \mathrm{C}$} & $30^{\circ} \mathrm{C}$ \\
\cline { 2 - 5 } & 87.5 & 100 & $/$ & $/$ \\
\cline { 2 - 5 } $\mathrm{P}_{\mathrm{el}} \mathrm{mGT}$ \\
{$[\mathrm{kW}]$} & 81.3 & 92 & 100 & $/$ \\
\cline { 2 - 5 } & 75.0 & 84 & 92 & $/$ \\
\cline { 2 - 5 } & 68.0 & 75 & 83 & 100 \\
\cline { 2 - 5 } & 50.0 & 53 & 59 & 75 \\
\cline { 2 - 5 } & 40.0 & 40 & 47 & 61 \\
\cline { 2 - 5 } & 35.0 & $/$ & 40 & 54 \\
\cline { 2 - 5 } & 25.0 & $/$ & $/$ & 40 \\
\hline
\end{tabular}

Tab. 2. Operating matrix of the system comparing power range of the T100 and the heavy-duty GT at different ambient conditions

The TOT is interested of any relation because the mGT TOT is kept constant at all operating conditions and the reduction that was aforementioned, has been consequently neglected through the new consideration on the minimum load. It follows then the relation maps obtained with equations 1-4: Fig. 10 related to the power and Fig. 11 related to the fuel flow. In addition, Tab. 2 and Tab. 3 reports the operating map of the duo, and how the part load of the two engine is associated one another. These maps are implemented into the interface between the test rig and the real time model, creating the connection between physical system and simulation environment.

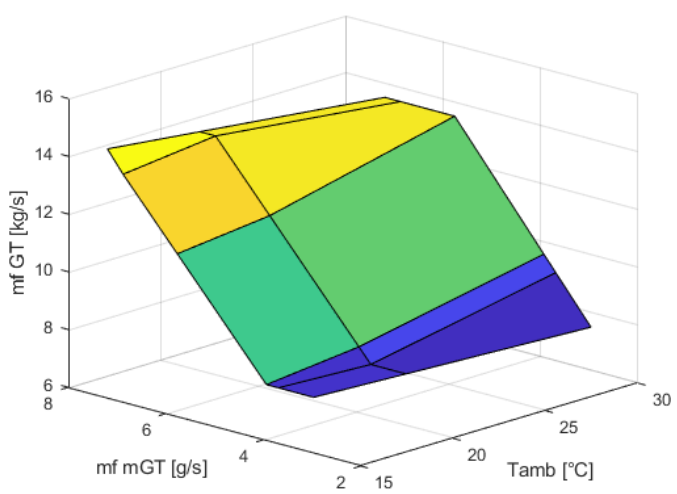

Fig. 11. Operating map linking mGT and heavy-duty GT fuel mass flow at different ambient temperature

\begin{tabular}{|c|l|r|r|r|}
\cline { 3 - 5 } \multicolumn{2}{c|}{} & \multicolumn{3}{c|}{$\mathrm{m}_{\mathrm{f}} \mathrm{GT}[\%]$} \\
\cline { 3 - 5 } \multicolumn{1}{c|}{} & $15{ }^{\circ} \mathrm{C}$ & $20^{\circ} \mathrm{C}$ & \multicolumn{1}{c|}{$30^{\circ} \mathrm{C}$} \\
\hline \multirow{4}{*}{$\begin{array}{c}\mathrm{m}_{\mathrm{f}} \mathrm{mGT} \\
{[\mathrm{kW}]}\end{array}$} & 7.2 & 100 & $/$ & $/$ \\
\cline { 2 - 5 } & 6.9 & 95 & 100 & $/$ \\
\cline { 2 - 5 } & 5.8 & 79 & 84 & 100 \\
\cline { 2 - 5 } & 3.9 & 54 & 58 & 71 \\
\cline { 2 - 5 } & 3.7 & $/$ & 55 & 67 \\
\cline { 2 - 5 } & 3.0 & $/$ & $/$ & 56 \\
\hline
\end{tabular}

Tab. 3. Operating matrix of the system comparing fuel mass flow of the T100 and the heavy-duty GT at different ambient conditions

\section{Conclusions}

\subsection{Replicability}

A methodology to develop a combined cycle emulator, i.e. a cyber-physical system composed of actual hardware (e.g. the microtubine, heat pump, thermal storage) and virtual hardware (e.g. steam bottoming plant) via the use of a microturbine has been presented. Great attention has been posed onto scaling up the mGT to emulate a heavy-duty GT. Considering the difference between the actual combined cycle and its emulator some considerations must be carried out for defining the link between the current microturbine operating condition and the equivalent heavy duty GT and GTCC operating condition. In this case, a variation in microturbine TOT was used to identify the MEL. Even though the work is focused on the Turbec T100, the same approach can be carried out considering i.e. a Capstone microturbine or a specific OEM heavy duty gas turbine. This paragraph describes a short vademecum for replicability of the work:

- An analysis of the available microturbine must be carried out beforehand, first of all, focusing on its performance deviations due to ambient temperature. This paper focuses on fuel flow, power, TOT and air mass flow ${ }^{1}$. TOT remains constant all over the microturbine operating envelop (see next point).

- In case of other microturbines, a focus on the difference in fuel consumption at minimum load can be taken into consideration in order to carried out the same comparison.

- The minimum load must be investigated. In this case a variation in TOT setpoint was adopted as the indicator for the minimum load for the microturbine, which is inherently variable-speed. If a variable minimum load is present in the engine control, then it can be treated as one of the previous variables, as a function of the ambient temperature. This is the turning point for the work, as it is very dependent to the specific microturbine and its control system.

\footnotetext{
1 Operating matrix of the system comparing power range of the T100 and the heavy-duty GT at different ambient conditions
} 
- Once the previous two points are defined, a performance analysis on the target heavy duty system must be carried out. Such analysis will provide the parameters corresponding to those investigated for the microtubine.

- The matrices linking the investigated parameters can be obtained similarly to Tab. 2 or Tab. 3 .

\subsection{Further developments}

The presented system is now installed in the laboratory of University of Genoa at Tirreno Power premises in Savona, Italy. The system is going to start an extensive experimental campaign to emulate the impact that the compressor intake temperature, conditioned by a dedicated heat pump and thermal energy storage, has on the combined cycle flexible behaviour. The scope is to focus on any strategy that augment the GTCC flexibility according to techno-economic constraints. Furthermore, the plant will be also used for educational/training purpose for the students/operators visiting the lab in order to take confidence with effect of ambient conditions on GTs and to operate an emulated power plant incorporating the real-time influence of the electrical market.

\section{Acknowledgement}

This project has received funding from the European Union's Horizon 2020 research and innovation programme under grant agreement

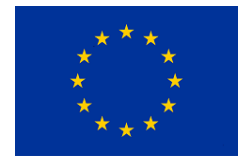
No 764706, PUMP-HEAT.

\section{References}

1. E. Pursiheimo, H. Holttinen, T. Koljonen, Inter-sectoral effects of high renewable energy share effects of high renewable energy share in global energy system Renewable Energy, 136 pp. 1119-1129 (2019)

2. www.baywa-re.com

3. F. Benhmad, J. Percebois, , Photovoltaic and wind power feed-in impact on electricity prices: The case of Germany, Energy Policy, 119 pp. 317-326 (2018)

4. S. Zalazar, E. Bonpard, A. Purvins, M. Masera, The impacts of an integrated European adjustment market for electricity under high share of renewables, Energy Policy, 136 (2020)

5. Relazione annuale e stato dei servizi, 31 marzo 2019, available at www.arera.it (2019)

6. H. Kobayashi, A. Hayakwa, K.D. Kunkuma, A. Somarathne, E.C. Okafor, Science and technology of ammonia combustion Proceedings of the combustion institute, 37, pp. 109-133 (2019)

7. M.R. Bothien, A. Ciani, J.P. Wood, G. Fruechtel, Sequential combustion in Gas
Turbines: the key technology for burning high hydrogen contents with low emissions, ASME Turbo Expo, Phoenix (USA) (2019)

8. S.G. Mosele, T. Garbarino, A. Schneider, L. Cozzi, A. Arnone, G. Goinis, S. Hedkvist, Compressor Retrofittable Solutions in HeavyDuty Gas Turbines for Minimum Environmental Load Reduction, E3S Web of Conferences SUPEHR19, 113, art. no. 01012 (2019)

9. A. Mehrpanahi, G.H. Payganeh, Multiobjective optimization of IGV position in a heavy-duty gas turbine on part-load performance, Applied Thermal Engineering, 125, pp. 1478-1489 (2017)

10. Y. Li, G. Zhang, Z. Bai, X. Song, L. Wang, Y. Yang, Backpressure adjustable gas turbine combined cycle: A method to improve partload efficiency, Energy Conversion and Management, 162, pp. 55-65 (2018)

11. D. Li, Y. Hu, D. Li, J. Wang, Combined-cycle gas turbine power plant integration with cascaded latent heat thermal storage for fast dynamic responses, Energy Conversion and Management, 183, pp. 1-13 (2019)

12. R. Guédez, J. Garcia, A. Nuutinen, G. Graziano, J. Chiu, A. Sorce, L. Piantelli, A. Traverso, B. Laumert, Techno-Economic Comparative Analysis of Innovative Combined Cycle Power Plant Layouts Integrated With Heat Pumps and Thermal Energy Storage, ASME Paper GT2019-91036, ASME Turbo Expo, Phoenix, (USA) (2019)

13. A. Sorce, A. Giugno, D. Marino, S. Piola, R. Guedez, Analysis of a Combined Cycle Exploiting Inlet Conditioning Technologies for Power Modulation, ASME Paper GT201991541, ASME Turbo Expo 2019, Phoenix (USA) (2019)

14. I. Rossi, L. Piantelli, A. Traverso, Gas Turbine Combined Cycle Flexibility: a Dynamic Model for Compressor Intake Conditioning Through a Heat-Pump, Journal of Engineering Gas Turbine and Power (under press) (2019)

15. Y. Watanabe, A. Traverso, Dynamic modeling and simulation of a heat pump system for enhancing cycle flexibility, E3S Web of Conferences, 113, art. no. 01007 (2019)

16. F. Caresana, L. Pelagalli, G. Comodi, M. Renzi, Microturbogas cogeneration systems for distributed generation: Effects of ambient temperature on global performance and components' behaviour, Applied Energy, 124 pp. 17-27 (2014)

17. M.L. Ferrari, A. Traverso, A.F. Massardo, Smart polygeneration grids: experimental performance curves of different prime movers, Applied Energy, 162 pp.622-630 (2016)

18. http://www.pumpheat.eu 